\title{
Sentidos de tempo livre para trabalhadores offshore
}

\author{
Meanings of free time for \\ offshore workers
}

Tielly Rosado MADERS ${ }^{1}$

Maria Chalfin COUTINHO ${ }^{1}$

\section{Resumo}

Este artigo apresenta resultados parciais da pesquisa que objetivou compreender quais os sentidos sobre tempo livre produzidos por trabalhadores offshore em seu cotidiano de trabalho. A pesquisa utilizou abordagem qualitativa, tendo como principal fonte de informação entrevistas compreensivas realizadas com trabalhadores de ambos os gêneros da Bacia de Campos/Rio de Janeiro. Foi possível consolidar dois eixos de análise: os tempos lá, relativos à vida dos trabalhadores quando estão embarcados nas plataformas de petróleo, e os tempos cá, referentes à sua vida em terra. Foram discutidos elementos substanciais acerca da vida cotidiana dos trabalhadores no período do embarque e as relações temporais concebidas em seu cotidiano de trabalho. Concluiu-se que as experiências temporais vivenciadas pelos trabalhadores offshore são intensas e pautadas na produção, enquanto os sentidos de tempo livre são de descanso e recuperação da força de trabalho.

Palavras-chave: Espaço e tempo; Percepção do tempo; Produção de sentidos; Trabalho confinado; Trabalho offshore.

\begin{abstract}
This article reports the partial results of a research that was aimed at understanding the meanings of free time attributed by offshore workers in their daily work. The qualitative approach was adopted for the research, which was carried out based on comprehensive interviews conducted with workers of Bacia de Campos (a coastal sedimentary basin of the Northern region of the state of Rio de Janeiro, Brazil). Two major aspects were analyzed: the time there, referring to the lives of workers while on board of offshore oil platforms and the time here, referring to their lives while on land. Substantial elements of the daily life of workers during their time on the platform and the temporal relationships established in their daily work were discussed. It was concluded that the temporal experiences of offshore workers are based on production, whereas free time means rest period and time to recover from the efforts and restore energy to continue the work.
\end{abstract}

Keywords: Space and time; Time perception; Production of meanings; Confined work system; Offshore work.

\footnotetext{
$\checkmark \nabla \nabla v$

1 Universidade Federal de Santa Catarina, Departamento de Psicologia, Programa de Pós-Graduação em Psicologia. R. dos Laranjais, 249, Bairro Morro das Pedras, 88066-067, Florianópolis, SC, Brasil. Correspondência para/Correspondence to: T.R. MADERS E-mail: <tiellypsi@gmail.com>.

Artigo elaborado a partir da dissertação de T.R. MADERS, intitulada "Trabalho e temporalidades: sentidos produzidos por petroleiros offshore". Universidade Federal de Santa Catarina, 2014.
} 
Este artigo apresenta resultados parciais da pesquisa de mestrado, a qual teve como objetivo compreender quais os sentidos sobre tempo livre produzidos por trabalhadores offshore, de ambos os gêneros, em seu cotidiano de trabalho. A pesquisa situa-se no campo da Psicologia Social do Trabalho e discorre sobre a temática da produção de sentidos a partir do Construcionismo Social. Em tal abordagem, a realidade é compreendida como uma construção social, vivenciada por meio do intercâmbio entre as pessoas que cotidianamente, ao conversarem, processam narrativas e produzem sentidos como forma de se situarem no mundo (Gergen, 2009; Pinheiro, 2004).

Em acordo com a posição epistemológica construcionista, tanto o sujeito como o objeto são concebidos como "construções sócio-históricas" que precisam ser problematizadas e desnaturalizadas (Spink, 2010, p.55). A realidade não existe desanexada da maneira como as pessoas a compreendem, pois as ações produzidas no cotidiano, no espaço/tempo do aqui e agora, constituem relações sociais que são sempre historicamente datadas e culturalmente localizadas (Berger \& Luckman, 2004; Spink, 2010).

A seguir, pontuam-se algumas configurações do trabalho offshore e expõem-se considerações sobre os tempos sociais na contemporaneidade. Após, apresentam-se o método e os resultados parciais da pesquisa, com enfoque nas temporalidades vividas pelos trabalhadores durante o período do embarque, os "tempos lá".

\section{Trabalho offshore}

A expressão offshore é aplicada, segundo Figueiredo (2012, p.19) "às atividades de exploração e produção de petróleo em alto-mar". A exploração do petróleo, "principal fonte de energia do século $X X^{\prime \prime}$, ganhou destaque e relevância mundial à proporção que avançou a industrialização (Figueiredo, 2012, p.41). Atualmente o petróleo encontra-se difundido na sociedade devido ao alto consumo de seus derivados (óleo combustível, óleo diesel, asfalto, plástico, produtos de limpeza, entre outros), e sua indústria mobiliza um enorme contingente de trabalhadores ao redor do mundo.
No contexto brasileiro, durante as décadas de 1980 e 1990, com a reestruturação produtiva e a introdução das tecnologias nas fábricas (Antunes, 2013), observa-se o cenário da reestruturação produtiva, marcado pelas políticas de ajuste neoliberal, com diversas mudanças: colocou o mercado como regulador da sociedade, desestruturou o Estado de Bem-Estar Social, abriu os mercados nacionais a fim de acirrar a competitividade entre as empresas, privatizou as empresas estatais e flexibilizou a legislação trabalhista (Antunes, 2002; Lapis, 2011). A Petrobras, após aprovação da Lei n 9.478, abriu o mercado para o investimento do capital privado (Barbosa, Borges, Cavalcanti, \& Portela, 2007), quebrando o monopólio sobre as atividades de "exploração, produção, refino e transporte de petróleo, derivados e gás natural, possibilitando que empresas operadoras e prestadoras de serviços, sejam elas nacionais ou estrangeiras, viessem a competir com a empresa estatal em todos esses segmentos de atividades" (Furtado, 2003, p.8).

Nesse cenário, ao longo dos anos 1990, a terceirização e precarização acentuaram-se no setor offshore, com destaque para a Bacia de Campos, RJ, principal região produtora do petróleo no Brasil, a qual contempla uma área em torno de 100 mil $\mathrm{km}^{2}$, de Vitória/ES a Arraial do Cabo/RJ (Clemente, 2012; Figueiredo, 2012; Ribeiro \& Sales, 2011).

O regime de trabalho offshore é distinto do da maior parte da população, compreendendo um período de 14 dias em confinamento nas plataformas marítimas e 21 dias em folga na terra para os trabalhadores concursados da Petrobras (chamados "próprios"), e 14 para os terceirizados (Leite, 2009). Devido ao grande contingente de terceirizados, a jornada 14×14 é predominante, porém, há muitas variações; dependendo da empresa e/ou da função de cada trabalhador, "um mergulhador chega a passar 28 dias confinado" (Maia, Gonçalves, Celestino, \& Figueiredo, 2003, p.3).

O ambiente de trabalho em uma unidade offshore implica alta periculosidade e insalubridade, pois há produtos químicos inflamáveis, riscos de incêndios, explosões, altos ruídos, calor extremo, ventilação inadequada, vazamentos de gases e vapores tóxicos (Figueiredo, 2012; Maia et al., 2003). 
Durante os 14 dias seguidos de embarque, ao término da jornada de trabalho, os trabalhadores permanecem em seu local de trabalho, em confinamento. Ao longo das 24 horas diárias, o trabalho se desenrola em dois turnos de revezamento. Os trabalhadores passam sete dias no turno da noite e os outros sete no turno do dia, revezando-se continuamente (Alvarez, Figueiredo, \& Rotenberg, 2010). Ainda, "a adaptação ao regime de turnos é sempre interrompida bruscamente pelo retorno ao ritmo doméstico e vice-versa" (Maia et al., 2003, p.3). No período de folga, os trabalhadores encontram-se de sobreaviso e ficam limitados aos espaços oferecidos pelas plataformas, os quais variam muito de uma para outra e podem contemplar camarotes, refeitório, sala de recreação, academia, etc. (Maia et al., 2003).

Desse modo, pode-se afirmar que o regime de embarque desorganiza a vida social dos trabalhadores, ao exacerbar a separação entre tempo/espaço de trabalho e vida privada/doméstica, fazendo com que ocorra uma interrupção/suspensão constante entre os períodos de embarque e a vida em terra (Barbosa et al., 2007; Sampaio, Borsoi, \& Ruiz, 1998).

\section{Temporalidades contemporâneas}

A compreensão acerca do tempo é fundamental para a organização do mundo social, já que é a partir da vivência temporal que é possível posicionar-se "perante a vida e a finitude desta", enquanto sujeito histórico e datado (Araújo \& Duque, 2012, p.7).

Desde as épocas remotas a sociedade mediu o tempo para estabelecer suas mais diversas atividades, os períodos ideais de colheita e plantio, assim como os períodos de celebração e festas (Venco, 2012). Cada momento era dispendido para uma atividade específica. A compreensão do tempo era orientada por essas tarefas e era utilizada como uma importante ferramenta de organização social (Cherman \& Vieira, 2008; Le Goff, 1979; Venco, 2012). Ao longo da história da sociedade capitalista, a construção do tempo afastou-se "dos códigos estabelecidos na agricultura familiar" e dos ritmos regidos pelo tempo da natureza, de modo que a compreensão acerca do tempo ganhou complexidade, pois o tempo passou a imperar - nessas novas sociedades -, em um sentido de uso econômico (Venco, 2012, p.100).

O acesso geral às mais diversas tecnologias juntamente com as transformações em curso no mundo do trabalho (tecnológicas, gerenciais e informacionais) apresentam novas configurações nas formas de gerir o tempo de trabalho, podendo o tempo assumir diversos sentidos e envolver mais dimensões do que aquelas propostas "no âmbito estrito do uso de instrumentos de medição, como relógio ou calendário" (Araújo, 2012, p.10).

Para Araújo e Duque (2012), as configurações do tempo na contemporaneidade sinalizam disparidades entre as temporalidades exigidas no cotidiano e as temporalidades determinadas pelos vários sistemas sociais existentes. Isto é, a noção de um "tempo mecânico, o tempo abstrato do relógio e outros instrumentos e formas de medição" (Araújo \& Duque, 2012, p.7), utilizada pelas sociedades ocidentais, entra em colapso quando as pessoas são, instantânea e simultaneamente, solicitadas para a resolução das mais diversas tarefas que perpassam a vida cotidiana, em que a própria separação entre o tempo/espaço de trabalho e o tempo/espaço de não trabalho, antes definidos e separados com clareza, se confundem (Araújo \& Duque, 2012; Cardoso, 2007; Venco, 2012).

A partir dessas interações vivenciadas e/ou instituídas socialmente, as pessoas produzem uma pluralidade de sentidos de tempo, conforme os contextos culturais e sociopolíticos em que vivem, com implicações em todas as esferas da vida social, revelando a atualidade da presente investigação (Araújo \& Duque, 2012; Venco, 2012).

\section{Método}

De acordo com Morin, Ciurana e Motta (2007, p.19), "ninguém pode basear um projeto de aprendizagem e conhecimento num saber definitivamente verificado e edificado sobre a certeza". 
Sendo assim, o método foi compreendido como um caminho, no qual foi possível (re)aprender, refletir e criar a cada passo do percurso.

O principal instrumento utilizado para levantar as informações foi a entrevista compreensiva, entendida como parte do processo de construção do objeto de estudo, e não apenas como uma técnica (Zago, 2003). A entrevista compreensiva é um processo que necessita da proximidade entre o pesquisador e o informante e, por não ter uma estrutura rígida, possibilita uma fala livre ao pesquisado, ampliando vários aspectos não abordados no roteiro (Zago, 2003).

As primeiras aproximações com o campo da pesquisa iniciaram ainda na etapa de construção do projeto, em que foram realizadas viagens frequentes ao Rio de Janeiro, região que comporta grande número de operações offshore. Ao longo da fase exploratória foram realizadas sete entrevistas com funcionários de empresas do ramo offshore, dirigentes sindicais e trabalhadores, com intuito de ampliar a compressão dessa realidade e aprimorar as perspectivas do campo de pesquisa; tais entrevistas foram consideradas complementares. A partir dos contatos e indicações levantadas, Macaé (cidade onde embarcam os trabalhadores da Bacia de Campos) revelou-se como um campo possível para a realização da pesquisa, de forma que todas as entrevistas da pesquisa foram realizadas em diferentes locais desta cidade.

Na cidade de Macaé, a pesquisadora entrou em contato com trabalhadores que, no momento das observações de campo, se encontravam no Sindicato dos Petroleiros do Norte Fluminense, no Sindicato dos Trabalhadores Offshore do Brasil ou no aeroporto da cidade, onde aguardavam o próximo embarque. Após os esclarecimentos sobre os objetivos da pesquisa e a assinatura do Termo de Consentimento Livre e Esclarecido, foram realizadas as entrevistas, gravadas em áudio e com duração entre $35 \mathrm{~min}$ e $1 \mathrm{~h} 40 \mathrm{~min}$. Nos Sindicatos foi cedida uma sala para a realização das mesmas, e no aeroporto as entrevistas foram realizadas nas salas de embarque.

Foi realizado um total de dez entrevistas. 56 Para efetivar a análise em profundidade foram utili- zados os seguintes critérios de diversidade: terceirizados e concursados da Petrobras; homens e mulheres; menor e maior tempo de embarque; e variedade de funções (cargos).

A partir de tais critérios, foram selecionadas seis entrevistas para serem analisadas em profundidade. Três dos entrevistados eram terceirizados: Walter (bombeiro, torrista, plataformista e auxiliar de plataforma, com 17 anos de embarque), Gustavo (engenheiro mecânico coordenador de equipes, com 2 anos de embarque) e Marília (nutricionista e comissária de bordo, com 3 anos de embarque); e outros três eram concursados da Petrobras: Patrícia (operadora de produção, com 10 anos de embarque), Tiago (auxiliar administrativo, com 10 anos de embarque) e Rafael (inspetor de ultrassom, com 33 anos de embarque). As demais entrevistas também foram consideradas complementares. Cabe ressaltar que todos os nomes dos entrevistados são fictícios.

O procedimento de análise do material iniciou-se com uma imersão no conjunto de informações levantadas, "procurando deixar aflorar os sentidos, sem encapsular os dados em categorias, classificações ou tematizações definidas a priori" (Spink \& Lima, 2004, p.83). A organização e a análise do material foram baseadas na análise temática de narrativas, a qual busca investigar principalmente qual conteúdo a narrativa comunica (Riessman, 2008). As narrativas foram organizadas em temáticas e articuladas com as proposições teóricas, refletindo o problema de pesquisa e os objetivos específicos, conforme apontado por Riessman (2008).

Foi possível consolidar dois eixos de análise, os quais abarcaram os "tempos lá", os aspectos que compreendem a vida dos trabalhadores quando estão embarcados nas plataformas de petróleo, e "os tempos cá", os aspectos que compreendem suas vidas em terra. A seguir, apresentam-se alguns resultados e discussões referentes ao período em que os trabalhadores estão embarcados, os "tempos lá".

O projeto de pesquisa foi submetido e aprovado pelo Comitê de Ética em Pesquisa com Seres Humanos da Universidade na qual se inserem as autoras, respeitando os parâmetros éticos vigentes 
na época, de acordo com a Resolução n 196/96, a qual:

Incorpora, sob a ótica do indivíduo e das coletividades, referenciais da bioética, tais como, autonomia, não maleficência, beneficência, justiça e equidade, dentre outros, e visa a assegurar os direitos e deveres que dizem respeito aos participantes da pesquisa, à comunidade científica e ao Estado (Brasil, 2012, p.1).

\section{Resultados e Discussão}

Para compreender as percepções dos trabalhadores sobre o tempo, é necessário conhecer o cotidiano de trabalho offshore, uma vez que o cotidiano é o lugar/base material onde as pessoas constroem suas experiências sociais e produzem sentidos (Berger \& Luckman, 2004).

Para Leite (2009), estar confinado é estar off da vida social. A condição de isolamento social e confinamento durante os 14 dias ininterruptos de trabalho, no mesmo local, ocasiona uma não divisão entre o espaço/tempo laboral e o pessoal/ privado (Figueiredo, 2012). Lociser (1995), em estudo com trabalhadores confinados, pondera que o efeito totalizante pode acontecer em condições de confinamento e periculosidade, em que o trabalhador é submetido por um longo período a um regime de trabalho em que há grande controle, normatização e pressão da gerência. Para Lociser (1995, p.79), "este efeito provocava uma forte tendência a 'instituir o total' no sentido de interferir na totalidade da vida do trabalhador (inclusive no período de folga)". Uma maneira encontrada para enfrentar o confinamento, conforme relatam as entrevistas, foi tentar separar os momentos do trabalho embarcado da vida pessoal em terra, como evidenciado na fala de um trabalhador:

A pessoa vai embarcar e tem que focar no trabalho, se não você fica doido, só quer descer [da plataforma], tudo te irrita. Foi uma forma que eu achei, assim: embarcou, você muda o botão, né? Como se pudesse fazer [risos]. Trabalho, só trabalho. Quando desce, troca de novo o botão, em terra é em terra, desliga do trabalho, é familia (Tiago).

Para Figueiredo (2012), a maioria dos trabalhadores atua em regime de doze horas de trabalho e doze horas de folga, sendo que, na primeira semana, cumprem-se as horas no turno diurno e, na segunda, no turno noturno, gerando mais um fator de estresse apontado pela entrevistada Marília: "... pior pra mim por causa da cama, travesseiro diferente, e balanço, balança bastante, ficava enjoada no começo, depois o labirinto acostuma, né? Mas aí você troca de turno e aí, ah, já viu, né? Tudo de novo". Alguns trabalhadores ainda estão submetidos ao sobreaviso, e suas jornadas podem exceder o período de 12 horas "por conta das demandas vinculadas à sua atividade" (Figueiredo, 2012, p.182).

Os horários e as atividades variam de acordo com as atividades/funções específicas de cada cargo e, ainda, de empresa para empresa. No caso dos trabalhadores entrevistados, pôde-se constatar que quatro apresentaram uma escala de turnos fixa, cada uma com suas especificidades, relacionadas às funções exercidas, conforme ilustrado a seguir:

Meu turno é de doze horas de trabalho, é das sete da manhã às dezenove e das sete da noite às sete da manhã. E tem alguém que me substitui a bordo, né? Meu back [expressão do entrevistado] ... (Gustavo).

Eu acho assim, eu trabalho das seis às dezoito, mas lá tem vários turnos, tem de seis às dezoito, dezoito às seis, de meio-dia a meia-noite, de meia-noite a meio-dia, são quatro turnos diferentes. Mas por eu ser comissária eu não tenho back, né?... . Então acaba se estendendo minha jornada, eu trabalho demais, eu não tenho nem tempo de pensar muita coisa. Ah, e eu estou presa lá, é muito trabalho, muito trabalho (Marília).

Em relação à expressão "back" utilizada por Marília e Gustavo, esta designa os colegas que substituem seu posto de trabalho no outro turno, no mesmo embarque.

Já em relação aos outros dois entrevistados, eles atuam em regime diverso do estipulado em 
seus contratos de trabalho - no caso de Rafael, o regime de $14 \times 14$ e, no caso de Tiago, $14 \times 21$ :

Hoje minha jornada não é mais $14 \times 21$, mas pra empresa eu continuo 14x21, mas nem sempre é assim, é meio que, vamos dizer assim, não é formalizado. Às vezes eu fico fazendo coisas no escritório e não embarco tanto (Tiago).

Lá, às vezes, dependendo da necessidade da plataforma, sua jornada de trabalho começa normalmente seis, sete da manhã, né? Precisou, eu vou. Dois, três dias, cinco dias. É difícil ficar porque a diária do inspetor é muito alta. Então eu sou a pessoa mal vista financeiramente [risos]. Apesar de ser 14×21, na realidade não é assim não (Rafael).

Apesar de os trabalhadores atuarem nos seus regimes formais de trabalho, observa-se que todos os entrevistados relataram já terem sido chamados pela empresa, muitas vezes, em caráter "emergencial", logo após terem desembarcado, o que configura o regime de sobreaviso. A ilustração a seguir expressa o que acontece com muitos trabalhadores offshore. Rafael foi entrevistado no aeroporto, algumas horas antes de embarcar novamente:

Tanto em terra quanto no trabalho, você passa a ser dono só do seu corpo, sabe? Você não pode estar doente, tem que estar cumprindo horário, tem limitações, fica dependendo sempre do serviço, você nunca pode fazer o que quer. Eu vejo os colegas aí, às vezes, querendo fazer curso e tudo mais, um projeto de vida. Mas como? Tem que se afastar, ficar sempre de sobreaviso. Eu mesmo desembarquei anteontem, foi anteontem? É, eu tive que fazer um treinamento na empresa, e nesse mesmo dia, foi ontem, eu vim pra cá, me chamaram e vou embarcar de novo. Sempre assim, precisou, eu vou (Rafael).

O "efeito totalizante" é acentuado pelos longos turnos, pelo descanso insuficiente e interrompido, pela troca de turnos e, ainda, pelos embarques sucessivos e pelo regime de sobreaviso 58 (Figueiredo, 2012):
Ah, bem estressante, é bem estressante, é muito diferente o estresse que a gente tem quando sabe que a gente tá confinado... . Tudo é muito intenso. Assim, todo mundo fala que quem embarca fica doido, porque as sensações lá [na plataforma] que a gente tem são tudo mais a flor da pele... se eu tivesse em terra é uma coisa, lá é gravissimo, é uma ofensa, mas eu acho que é pela jornada de trabalho, né? É pelo estresse de estar confinado, de não ter lazer, de não ter nada (Marília).

Para Figueiredo (2012), cria-se um deslocamento social com repercussões nas relações com a família, amigos, vizinhos, parentes, o que afeta o convívio social e a vida afetiva dos embarcados, fazendo com que compreendam suas vidas de maneira dicotômica e exacerbada (Leite, 2009). Tais fatores são acentuados quando se trata dos terceirizados, pois seu tempo de folga é significativamente menor quando comparado aos trabalhadores próprios, fazendo com que sintam com maior frequência e intensidade os aspectos dos embarques sucessivos e do regime do confinamento, como se observa no relato de Gustavo:

Ou curte muito esse regime de trabalho, ou detesta, não quer mais trabalhar dessa forma, se sente preso lá. Porque o trabalho offshore, você tem duas formas gritantes de trabalhar. Ou você se vê como preso, numa prisão durante seis meses do ano; ou você se vê livre durante seis meses do ano. Você pode enxergar de duas formas, é muito oito ou oitenta, né? ... .

Nesse cenário, o trabalho offshore se configura como um contexto de trabalho produtor de sofrimento e, em decorrência, os trabalhadores atribuem ao tempo um sentido de perdido, e ao trabalho o sentido de penosidade. O trabalho penoso "diz respeito aos contextos de trabalho geradores de incômodo, esforço e sofrimento físico e mental, sentido como demasiados, sobre os quais o trabalhador não tem controle" (Sato, 1993, p.197).

Mesmo no tempo livre do trabalho, as ações nas plataformas são realizadas dentro de regras de conduta específicas e em espaços compartilhados 
e vigiados pela gerência (Figueiredo, 2012). Para Venco (2012), o capitalismo, enquanto um sistema de controle de tempo, "se empenha em imprimir maior velocidade aos ritmos de trabalho, concomitantemente ao desenvolvimento das tecnologias" (Venco, 2012, p.101). Em seu processo de trabalho, os trabalhadores offshore vivenciam um tempo calcado na rotatividade, orientado pela normalização de regras e procedimentos, pelo controle a partir de normas de disciplina, pelas máquinas e pela tecnologia, sendo muito veloz o tempo que marca as tarefas (Castro \& Vinagre, 2009).

Assim, para Castro e Vinagre (2009), os trabalhadores offshore concebem o tempo de forma paralela, pois, além da condição de confinamento e do acelerado processo de produção, todo o tempo de embarque é percebido com uma intensidade "avassaladora", de maneira "pesada", ou seja, os trabalhadores atribuem ao tempo em que se encontram embarcados um sentido dedicado totalmente ao trabalho, desvinculados que se sentem do tempo da família, do tempo dos amigos, do tempo do lazer e de quaisquer outros tempos e atividades sociais externas às plataformas marítimas (Castro \& Vinagre, 2009).

Castro e Vinagre (2009) apontam que o sentido do tempo se apresenta como um elemento estressante para os trabalhadores embarcados. As horas no embarque são marcadas "como um peso, um fardo... o tempo não é newtoniano, objetivo e constante" (Castro e Vinagre, 2009, p.5), não se encontra nos ponteiros do relógio. Essa questão foi apontada pelos autores em uma pesquisa realizada com trabalhadores offshore:

O petroleiro sabe que seu tempo de trabalho efetivo, seu descanso, a quantidade de trabalhos realizados e o tempo de duração de cada atividade são criteriosamente aferidos. Assim sendo, é interessante perceber em sua fala que, quando ele se refere ao "tempo real" indica, na mesma frase, um outro tempo, percebido em termos bem coercitivos "o tempo todo" (Castro \& Vinagre, 2009, p.6).

Dessa forma, todo o período de embarque é marcado por sentimentos de ansiedade, estresse, cansaço, peso e prisão, e o tempo livre é um tempo destinado à reposição de forças para o trabalho. Todos os entrevistados apontaram um sentido comum: um tempo destinado à reposição física e ao descanso, como se pode observar no relato de Walter: "Meu tempo livre é o quê? Você tem que descansar. Tem que dormir, né? Pra recuperar o que você perdeu". Ou também no relato de Tiago: "São doze horas, né? Que você tem folga. Não tem muita opção... . E aí você toma banho, descansa e já dorme". Ou ainda, como vemos na fala de Marília: "Não tem muito lazer não, a gente sempre tá cansado, é mais pra descansar mesmo".

Apesar de alguns entrevistados utilizarem alguns espaços das plataformas no tempo liberado do trabalho, a maioria utiliza esse tempo para descansar. De acordo com Aquino e Martins (2007, p.485), o tempo livre do trabalho configura-se como "um tempo voltado para atividades de reposição física e mental" , ou seja, de recuperação para voltar ao trabalho.

Em geral, os espaços oferecidos nas plataformas fora do expediente do trabalho são semelhantes para a maioria das pessoas entrevistadas, a saber: sala de televisão e/ou cinema, sala de jogos, academia, piscina, salas de computadores com internet Wi-Fi e sala de leitura. Segundo Figueiredo (2012), a maioria das plataformas oferece esses espaços. Algumas apresentam, ainda, uma estrutura diferenciada, com quadra de futebol, sala de jogos - incluindo videogames, mesas de pingue-pongue e sauna (Figueiredo, 2012, p.203). Porém, como visto acima, a maioria dos trabalhadores entrevistados não ocupa esses espaços, pois ao final da jornada estão sempre exaustos.

Coelho e Paparelli (2010) observam que as vivências dos trabalhadores offshore são muito peculiares, assim como sua compreensão acerca do tempo. É uma relação espaço-tempo diferente daquela que é compartilhada socialmente, ou seja, a intensidade e o ciclo de embarques geram uma noção temporal singular, como se observa no relato de Gustavo:

Essa segunda etapa embarcado [referindo-se à segunda semana do embarque], de 15, 15, 15, 15, me dá muita ansiedade, me deixa muito acelerado, eu estou sempre contando 
tempo, estou sempre, sempre, sempre contando. Quando eu estou a bordo, eu estou contando tempo pra descer, quando eu chego aqui [em terra] eu estou contando meu tempo... de folga pra aproveitar. Então, eu fico muito ansioso, muito agitado, muito, pra mim é ruim, eu estou sempre, sempre contando tempo, sabe?

Considerando a assimetria de tempos de trabalho e folga, acentuada no caso dos trabalhadores terceirizados, que se desenvolvem com velocidades distintas, considera-se por fim que os trabalhadores offshore vivem outro tempo - um tempo regressivo -, conforme apontado por Figueiredo (2012, p.195) como o "tempo da ampulheta":

O tempo a bordo é regressivo, né? [risos]. A gente conta assim, o tempo a bordo funciona de trás pra frente em vez de frente pra trás [risos]. Geralmente a gente se encontra no navio e fala: "E aí, faltam quantos dias?" "E aí, tá há quanto tempo aí?" "Ah, faltam cinco pra desembarcar" "Ah, desembarco amanhã" "Pô, beleza, tá bem hein, vai desembarcar amanhã, não sei o que" [risos] rola até uma zoação [risos]. Tá pra desembarcar, o outro tá lá gorando "liiih, o voo não vem" "liiih esse mau tempo aí, né?" "Vi a previsão do tempo, vai chover pra cacete" [risos] "Não vai ter voo". Geralmente é falado direto com quem vai desembarcar, então, por isso que eu falo assim: o tempo é regressivo. A gente tá sempre contando pra descer (Gustavo).

\section{Considerações Finais}

Neste artigo foram apresentados recortes de uma pesquisa que objetivou compreender e analisar as narrativas produzidas sobre o tempo livre no cotidiano de trabalho de petroleiros offshore da Bacia de Campos, RJ. Por meio da análise das narrativas dos sujeitos, foi possível compreender diversos aspectos que compõem suas vidas cotidianas nas plataformas de petróleo em alto-mar.

A configuração do regime offshore revelou60 -se como um contexto de trabalho adoecedor, caracterizado por um expediente de 12 horas exaustivas de trabalho, com turnos de revezamento e estado de sobreaviso, distância da família e da vida em terra como um todo, convívio prolongado com os colegas de trabalho, falta de privacidade e dificuldades de adaptação ao trabalho noturno e ao sono, sentimentos de ansiedade e estresse extremos e constantes, acentuados pelo confinamento e pelos sucessivos embarques/desembarques, os quais rompem bruscamente os vínculos sociais e desorganizam os pensamentos, sentimentos e a vida cotidiana dos trabalhadores.

Tais aspectos reiteram a necessidade de se problematizarem as condições em que se desenrola o trabalho offshore, em busca de "mudanças estruturais e organizacionais do mercado de trabalho e das empresas" (Seligmann, Bernardo, Maeno, \& Kato, 2010, p.189), como a equiparação dos direitos, remuneração, jornada e benefícios dos trabalhadores terceirizados aos dos trabalhadores próprios.

As narrativas dos entrevistados em relação ao tempo dedicado ao trabalho revelam sentidos associados ao trabalho pesado e penoso. $O$ desgaste decorrente da permanência num ambiente de alto risco, em regime de turnos e sobreaviso, somado à intensificação da velocidade da produção, é acentuado pela vivência do confinamento e implica "desgaste para sua saúde física, podendo também levar a um desgaste mental" (Coutinho, Diogo, \& Joaquim, 2011, p.232).

Em relação às atividades realizadas nas plataformas, foi possível identificar similaridades nas narrativas. Todos os trabalhadores disseram utilizar as horas livres para reposição e descanso, com atividades de alimentação, higiene e repouso. Todos também argumentaram que o tempo liberado do trabalho é muito curto. Assim, estar embarcado é estar todo tempo focado no trabalho. Tempo livre embarcado é tempo de descanso.

Os discursos dos trabalhadores entrevistados revelam o quanto o tempo de trabalho se estende e invade os tempos liberados do trabalho na plataforma. Essas experiências temporais pautadas na produção reiteram o quanto os tempos sociais contemporâneos se configuram como "objetivação 
econômica e como forma social de dominação" (Cardoso, 2007, p.29), fazendo com que o trabalhador, cada vez mais, se esvazie do seu próprio tempo. A cultura temporal contemporânea é caracterizada pelo ritmo acelerado de relações que as pessoas constroem entre si, com as coisas e com os lugares. A existência de uma pluralidade de tempos sociais, acentuada pela inovação tecnológica, acaba por invadir e sobre determinar todo e qualquer tempo social (Venco, 2012).

Num momento em que há um grande aumento do contingente de trabalhadores offshore no Brasil e no mundo, principalmente com a descoberta recente do pré-sal em territórios brasileiros, ressalta-se a necessidade de pesquisas que investiguem esse contexto de trabalho e ofereçam resultados consistentes para a melhora efetiva das condições laborais e para uma possível reestruturação da jornada 14×14, uma vez que a terceirização, caracterizada pela precariedade e pelos acidentes de trabalho, cresce demasiadamente nesse setor.

Por fim, a pesquisa em Psicologia com base no Construcionismo Social pode utilizar a narrativa como forma de dar conta de uma realidade tomada como uma construção social (Bruschi \& Guareschi, 2007). Assim, a narrativa foi uma alternativa utilizada para, por meio de palavras, re-narrar a realidade dos trabalhadores offshore e realçar que as experiências vividas cotidianamente nas plataformas são construções sociais específicas contemporâneas, próprias de uma sociedade capitalista voltada para o trabalho.

\section{Colaboradores}

Em todas as etapas da construção do artigo, desde a concepção e desenho, análise e interpretação dos dados e revisão do mesmo, houve contribuição de ambas as autoras.

\section{Referências}

Alvarez, D., Figueiredo, M., \& Rotenberg, L. (2010). Aspectos do regime de embarque, turnos e gestão do trabalho em plataformas offshore da Bacia de Campos
(RJ) e sua relação com a saúde e a segurança dos trabalhadores. Revista Brasileira de Saúde Ocupacional, 35(122), 201-216. http://dx.doi.org/10.1590/\$0303-76 572010000200004

Antunes, R. (2002). Os sentidos do trabalho: ensaios sobre a afirmação e a negação do trabalho ( $6^{\mathrm{a}} \mathrm{ed}$.). São Paulo: Boitempo.

Antunes, R. (2013). Riqueza e miséria do trabalho no Brasil II. São Paulo: Boitempo.

Aquino, C. A. B., \& Martins, J. C. O. (2007). Ócio, lazer e tempo livre na sociedade do consumo e do trabalho. Revista Mal-estar e Subjetividade, 7(2), 479-500. Recuperado em junho 28, 2016 de http://www.ufsj. edu.br/portal-repositorio/File/dcefs/Prof._Adalberto_ Santos/4-ocio_lazer_e_tempo_livre_na_sociedade_ do_consumo_e_do_trabalho_22.pdf

Araújo, E., \& Duque, E. (2012). Os tempos sociais e o mundo contemporâneo. Um debate para as ciências sociais e humanas. Portugal: Centro de Estudos de Comunicação e Sociedade.

Araújo, E. (2012). A espera e os estudos sociais do tempo e sociedade. In E. Araújo \& E. Duque (Eds.), Os tempos sociais e o mundo contemporâneo. Um debate para as ciências sociais e humanas (pp.9-26). Portugal: Centro de Estudos de Comunicação e Sociedade.

Barbosa, S. C., Borges, L. O., Cavalcanti, E. A. F., \& Portela, S. A. (2007). A Petrobras: o contexto socioeconômico e o modelo gerencial. In L. O. Borges \& S. C. Barbosa (Orgs.), Aspectos psicossociais do trabalho dos petroleiros: dois estudos empíricos no Rio Grande do Norte (pp.59-86). Natal: Universidade Federal do Rio Grande do Norte.

Berger, P., \& Luckmann, T. (2004). Modernidade, pluralismo e crise do sentido: a orientação do homem moderno. Petrópolis: Vozes.

Brasil. Ministério da Saúde. (2012). Resolução nº 196/96, versão 2012. Recuperado em junho 28, 2016, de http:// conselho.saude.gov.br/web_comissoes/conep/aquivos/ resolucoes/23_out_versao_final_196_ENCEP2012. pdf

Bruschi, M. E., \& Guareschi, N. M. F. (2007). A narrativa como escrita dos trabalhos em construcionismo social. In Anais Eletrônicos do $14^{\circ}$ Encontro Abrapso. Recuperado em agosto 29, 2015, de http://www. abrapso.org.br/siteprincipal/anexos/AnaisXIVENA/ conteudo/pdf/trab_completo_275.pdf

Cardoso, A. C. M. (2007). Tempos de trabalho, tempos de não trabalho: disputas em torno da jornada do trabalhador. São Paulo: Annablume.

Castro, A. C., \& Vinagre, R. R. (2009, Outubro). A percepção do tempo subjetivo e o estresse no trabalho offshore. In XXIX Encontro Nacional de Engenharia de Produção (ENEGEP), Salvador. Recuperado em junho 10, 2012, de http://www.abepro.org.br/biblioteca/ enegep2009_TN_STO_094_634_13665.pdf 
Cherman, A., \& Vieira, F. (2008). O tempo que o tempo tem: porque o ano tem 12 meses e outras curiosidades sobre o calendário. Rio de Janeiro: Jorge Zahar.

Clemente, C. C. (2012). Entre o mar e a terra: uma antropologia do trabalho offshore. Crítica e Sociedade, 2(2), 159-175. Recuperado em dezembro 5, 2013, de http://www.seer.ufu.br/index.php/criticasociedade/ article/view/21947

Coelho, L. L. V., \& Paparelli, R. R. (2010). A experiência do trabalhador offshore: o caso de operadores de ROV. In Anais do Seminário de Saúde do Trabalhador de Franca, Franca, SP.

Coutinho, M. C., Diogo, M. F., \& Joaquim, E. P. (2011). Cotidiano e saúde de servidores vinculados ao setor de manutenção em uma universidade pública. Revista Brasileira de Saúde Ocupacional, 36(124), 227-237. http://dx.doi.org/10.1590/S03037657201100020 0006

Figueiredo, M. (2012). A face oculta do outro negro: trabalho, saúde e segurança na indústria petrolífera offshore da Bacia de Campos. Niterói: Universidade Federal Fluminense.

Furtado, A. T. (2003). Mudança institucional e inovação na indústria brasileira de petróleo. In Coloquio Internacional "Energia, Reformas Institucionales y Desarrollo em América Latina" (ERID), Universidade PMF de Grenoble, México, 5-7. Recuperado en Septiembre 10, 2013, de http://www.posgrado. economia.unam.mx/p-cientifica/coloquio-erdal/ 10CaAndreFurtadoPortugLtt.pdf

Gergen, K. J. (2009). O movimento do construcionismo social na Psicologia moderna. Revista Internacional INTERthesis, 6(1), 299-325. http://dx.doi.org/10.5007/ 1807-1384.2009v6n1p299

Lapis, N. L. (2011). Acumulação flexível. In A. D. Cattani \& L. Holzmann (Orgs.), Dicionário de trabalho e tecnologia (2a ed., pp.27-32). Porto Alegre: Zouk.

Le Goff, J. (1979). Para um novo conceito de Idade Média: tempo, trabalho e cultura no ocidente. Lisboa: Estampa.

Leite, R. M. S. C. (2009). Vida e trabalho na indústria de petróleo em alto mar na Bacia de Campos. Ciência e Saúde Coletiva, 14(6), 2181-2189. http://dx.doi.org/ 10.1590/S1413-81232009000600025

Lociser, E. (1995). A procura da subjetividade: a organização pede análise. In E. Davel \& J. Vasconcellos (Orgs.), Recursos humanos e subjetividade (pp.68-79). Petrópolis: Vozes.

Maia, L. X., Gonçalves, M. S., Celestino, P. G., \& Figueiredo, M. G. (2003). Um diagnóstico da organização do trabalho nas plataformas petrolíferas da Bacia de Campos e a influência dos investimentos em meio ambiente, saúde e segurança. In XXIII Encontro Nacional de Engenharia de Produção, ENEGEP, Ouro
Preto. Recuperado em outubro 26, 2012, de http:// www.abepro.org.br/biblioteca/ENEGEP2003_TRO 401_0679.pdf

Morin, E., Ciurana, E. R., \& Motta, R. D. (2007). Educar na era planetária (2a ed.). São Paulo: Cortez.

Pinheiro, O. G. (2004). Entrevista: uma prática discursiva. In M. J. P. Spink (Org.), Práticas discursivas e produção de sentidos no cotidiano: aproximações teóricas e metodológicas (3a ed., pp.156-187). São Paulo: Cortez.

Ribeiro, A. M. M., \& Sales, V. L. F. (2011). Experiências de (não) reconhecimento entre os trabalhadores offshore na bacia de Campos: uma abordagem a partir de Axel Honneth. Vértices, 13(2), 45-59. http://dx.doi.org/10. 5935/1809-2667.20110013

Riessman, C. K. (2008). Narrative methods for the human sciences. Califórnia: Sage.

Sampaio, J., Borsoi, I., \& Ruiz, E. (1998). Saúde mental e trabalho em petroleiros de plataforma: penosidade, rebeldia e conformismo em petroleiros de produção (onshore/offshore) no Ceará. Fortaleza: Flacso.

Sato, L. (1993). A representação social do trabalho penoso. In M. J. Spink (Org.), O conhecimento no cotidiano: as representações sociais na perspectiva da psicologia social (pp.188-211). São Paulo: Brasiliense.

Seligmann, S. E., Bernardo, M. H., Maeno, M., \& Kato, M. (2010). O mundo contemporâneo do trabalho e a saúde mental do trabalhador. Revista Brasileira de Saúde Ocupacional, 35(122), 187-191. http://dx.doi. org/ 10.1590/S0303-76572010000200002

Spink, M. J. (2010). Linguagem e produção de sentidos no cotidiano. Rio de Janeiro: Centro Edelstein de Pesquisas Sociais.

Spink, M. J. P., \& Lima, H. (2004). Rigor e visibilidade: a explicitação dos passos da interpretação. In M. J. P. Spink (Org.), Práticas discursivas e produção de sentidos no cotidiano: aproximações teóricas e metodológicas (3a ed., pp.71-99). São Paulo: Cortez.

Venco, S. (2012). A história e a atualidade da compressão do tempo e do espaço. In E. Araújo \& E. Duque (Eds.), Os tempos sociais e o mundo contemporâneo: um debate para as ciências sociais e humanas (pp.99-116). Portugal: Centro de Estudos de Comunicação e Sociedade.

Zago, N. (2003). A entrevista e seu processo de construção: reflexões com base na experiência prática de pesquisa. In N. Zago, M. P. Carvalho, \& R. A. T. Vilela (Orgs.), Itinerários de pesquisas: perspectivas qualitativas em sociologia da educação (pp.287-309). Rio de Janeiro: DP\&A.

Recebido: dezembro 10, 2015

Versão final: março 18, 2016

Aprovado: março 31, 2016 